\title{
Las aventuras de la moneda viviente: del papel moneda al bitcoin
}

\section{As aventuras da moeda viva: do papel moeda ao bitcoin}

\author{
GONZALO AGUIRRE
}

Se asume que la moneda bítica (bitcoin) se diferencia de la moneda estatal en que la primera no tiene respaldo de un Banco Central. Eso implica desconocer la lógica ontológica de generación de valor. Ningún Banco Central crea una moneda cuya confianza no preexista a su creación. Así, ningún Banco Central crea la confianza que respalda a la moneda; lo único que hace es, como su nombre lo indica, centralizarla.

\section{II}

La lógica o tecno-lógica que subyace a la creación de confianza de la moneda bítica es la misma que la de la moneda estatal, o la de la moneda imperial romana o la de cualquier otra moneda: una cadena de bloques (blockchain) de transacciones, es decir el atestado de una serie de intercambios entre personas (entiéndase persona en el sentido no material del término). Esa serie, en la fricción social generada con sus idas y venidas, genera valor-confianza el cual, a su vez, es condensado en un símbolo de todos esos intercambios: la moneda. Las monedas no se crean, son más bien el síntoma de la creación de valor-confianza. Podemos enumerar sumariamente tres tipos de cadenas de bloques de confianza: el antiguo basado en el bloque de gastos sacrificiales, el cristiano basado en el bloque de deuda padre-hijoespíritu santo (símbolo a su vez de una Nueva Alianza), y el bloque moderno basado en la transformación de la confianza cristiana en fe protestante ${ }^{2}$. Esta transformación luterana (de la cual se cumplieron 500 años en octubre de 2017),

\footnotetext{
${ }^{1}$ Licenciado en Ciencia Política (UBA) y Doctor en Filosofía (Universidad de Barcelona). Profesor Adjunto de "Teoría del Estado", Facultad de Derecho (UBA).

${ }^{2}$ Gilles Deleuze rastrea el paso de los Estados pre-cristianos (imperiales y despóticos) a los Aparatos de Estado cristianos (tendencialmente nacionales) que habrán de dar lugar a los Estados Nación (de Derecho) modernos capitalistas, a través de la mutación del orden de confianza de tres ejes de generación de valor: la renta absoluta, los trabajos públicos y los impuestos. Estos tres puntos de apropiación monopolística dan lugar a una Tierra, un Trabajo y una Moneda reunidos en la figura del déspota en tanto propietario público de esa Tierra, ese Trabajo y esa Moneda. La nueva Moneda (apta para expresarse en papel) habrá de surgir de un lento proceso de privatización o disgregación de esa propiedad pública en micro propiedades públicas que llamamos propiedad privada, cuyo soporte es un individuo en tanto persona jurídica. Resulta clave para comprender este pasaje la concepción mercantilista del nuevo agenciamiento moderno de creación de valor. Al respecto pueden consultarse clases 5-7 de Derrames II; o también Mil mesetas, mesetas 12 y 13. También el cap. VI de Las palabras y cosas de Foucault. Allí puede leerse: "Si ha sido posible creer que el mercantilismo confundía la riqueza y la moneda, esto se debe sin duda a que la moneda tiene para él el poder de representar toda riqueza posible, ya que es el instrumento universal del análisis y de la representación de ella, porque recubre, sin residudos, el conjunto de su dominio." (p. 173).
} 
implicó una transferencia en el asiento contable de la deuda/culpa (Schuld) de los participantes del protocolo de confianza cristiano: en vez de estar del dado del Debe, la Deuda pasó a estar del lado del Haber. Según Lutero, el Amor de Dios ha de predominar por sobre su Ira. Aún cuando esto no pueda confirmarse hasta el Juicio Final, sí cabe tener fe en la Gracia divina, e ir tratando de ganarse esa Gracia (de todos modos ya cuasi-ganada) entregándose a la faena terrenal. Hete aquí el origen del Capitalismo y la "acumulación originaria" (de Capital) a partir de la nueva alianza o, al decir de Max Weber, de la ética protestante que podría resumirse en la divisa: hay que tener fe en la confianza cristiana.

A partir de aquí nace una nueva cadena de bloques moderna (Trabajo-VidaLenguaje $)^{3}$ que será condensada en y por los Estados-Nación. Si la moneda antigua era la del César y la moneda cristiana era la de Dios, la moneda moderna será la moneda de la Nación. La moneda es siempre intangible porque su valor lo es. La incorporación del papel al modo expresivo de esa intangibilidad fue síntoma de la aceleración creciente en los intercambios y transacciones cuya simbolización quedaba de otro modo crecientemente atrasada. Los Bancos Centrales responden al intento original de evitar ese atraso simbólico-cambiario procurando que se exprese en moneda tangible todo el valor intangible que se está produciendo en una determinada cadena de bloques entendida nacionalmente.

III

La tendencia contemporánea que lleva a definir los Estados-Nación en términos territoriales y tangibles, y no en términos de bloques de confianza o contratos (en la terminología contractualista del siglo XVIII) de relaciones o transacciones intangibles, procede de la tendencia a desatender cualquier enfoque que pudiera abordar genealógica o afectivamente al fenómeno estatal. El trauma de la territorialidad que conlleva de base casi toda Teoría del Estado (un Estado siempre tiene un territorio y se define por él y sus límites) hace pensar que los bitcoins utilizan una tecnología novedosa por no ser territoriales, cuando más bien lo que hacen es mostrar que todo valor es intangible y que lo modos de simbolizar su producción tienden siempre a decrecer en su capacidad. En ese sentido podría decirse que el papel resulta ahora tan lento como lo fuera la moneda metálica en su momento; $y$, análogamente, que el papel-moneda fue tan difícil de comprender en el

\footnotetext{
${ }^{3}$ Título del capítulo VIII de Las palabras y las cosas. En sus primeros párrafos puede leerse: "En una primera fase -que se extiende cronológicamente de 1775 a 1795 y cuya configuración puede dibujarse a través de las obras de Smith, Jussieu y Wilkins-, los conceptos de trabajo, de organismo y de sistema gramatical fueron introducidos -o reintroducidos con un status especial- en el análisis de las representaciones y en el espacio tabular en el cual se desplegaba ésta hasta ahora." (op.cit., p. 245) "Toda riqueza es amonedable; así es como entra en circulación. De la misma manera, todo ser natural es caracterizable y podía entrar en una taxinomia; todo individuo era nombrable y podía entrar en un lenguaje articulado; toda representación era significable y podía entrar, para ser conocida, en un sistema de identidades y de diferencias." (op. cit., p. 173)
} 
siglo XVIII como lo es ahora el bit-moneda o bitcoin. La singularidad de esta última moneda radica en que su expresividad tampoco es tangible. Podría decirse que expresa intangiblemente (según patrones bítico-binarios de flujo eléctrico informacional), un valor que de por sí es también intangible. Que por ello resulte más fluida que la moneda nacional-estatal, aún cuando esta pueda traducirse a código bítico (o dinero electrónico), no habilita a sostener que no tiene ningún Banco Central que la respalde. El banco central de los bitcoins es la WebWordWide constituida por los usuarios de ese Gran Protocolo de transacciones. Al interior de ella, el protocolo de cadena de bloques podrá ir generando diversos tipos de moneda a partir de los excedentes bíticos del Gran Flujo Electrónico.

IV

Diríase que en este escenario los aparatos de Estado parecen estar tratando de concentrar toda la fuerza expresiva de valor bítico en los bitcoins, a los cuales procuran reducir a la lógica estatal difundiendo por todos los medios posibles el aumento de su valor medido en moneda nacional o internacional (el aumento del valor de un bitcoin se mide en dólares, y no en la capacidad de codificar o simbolizar transacciones que tiene). Ahora bien, esta maniobra quizás no pueda evitar que el aparato de Estado se convierta al "Bitcoinismo", como en su momento el Imperio Romano se convirtió el Cristianismo ${ }^{4}$ Y es que si la moneda del César deja de expresar valor, por más monedas que se recauden siempre serán insuficientes con respecto al poder valorativo de la moneda de Dios generada por una nueva alianza o cadena de bloques. Asimismo, si la lógica estatal de recaudación de tributos sigue sosteniéndose en una teoría del Estado que depende de nociones-fantasma como territorio o tangibilidad, su capacidad recaudatoria irá decreciendo cuánto más valor-en-falso recaude. Mientras se define si los bits se convierten al Estado o el Estado al bit (se trata siempre de atender a la fuente Web y a la reproducción de sus condiciones materiales de existencia), la lógica tributaria estatal puede al menos procurar desembarazarse de las ya obsoletas nociones (o prejuicios) de "territorio" y "cosa tangible" que resienten su funcionamiento. La lógica dividual, que ha indicado hace más de un cuarto de siglo Gilles Deleuze para las sociedades de control, no puede seguir expresándose según la lógica individual contractualista. Más bien impulsa cambios de agenciamiento cuya comprensión requiere, a su vez, un cambio en el régimen de atención epistémica que llevamos adelante. Pensadores como

\footnotetext{
4 Se diría que el Imperio Romano intentó también reducir el nuevo valor cristiano a su lógica, "recaudándolo" como tributo tangible (carnal) en la arena gladiadora del Circo, último gran centro recaudatorio romano. Pero la lógica de la nueva alianza resultó invencible: poniendo la otra mejilla la crueldad romana quedó transferida a la piedad cristiana. Habrá que atender a si la lógica bítica puede presentar un silogismo transferencial de este tipo, o si se reduce a un razonamiento más o menos herético de corte estatal. Para ello "los mineros" debieran dejar de "minar" la Web, y no parece que eso vaya a ocurrir: la inflación bítica concentrada propagandísticamente en los bitcoins hará que su eclosión programada tenga unos rindes de frustración tales que los hijos pródigos regresen finalmente a la casa estatal que gastará muchos dólares en darles la bienvenida.
} 
Gilles Deleuze o Gilbert Simondon han trabajado ya desde mediados del siglo XX en esa dirección comprensiva. Es así que recién ahora comienza a atisbarse el sentido de aquella frase que en 1970 Michel Foucault escribiera al arranque de su recepción de los libros de Gilles Deleuze Différence et répétition y Logique du sens (ambos de 1969): "Durante mucho tiempo creo que esta obra girará por encima de nuestras cabezas, en resonancia enigmática con la de Klossowski [posible alusión a La monnaie vivante de 1970 ], otro signo mayor y excesivo. Pero tal vez un día el siglo será deleuzeano." ${ }^{5}$

\section{Referências}

DELEUZE, Gilles, Derrames II. Buenos Aires: Cactus, 2017.

DELEUZE, Gilles. GUATARRI, Félix, Mil mesetas. Capitalismo y esquizofrenia. Valencia: Pretextos, 1994 .

FOUCAULT, Michel, Las palabras y cosas. Una arqueología de las Ciencias Humanas.

México: Siglo XXI, 1993.

FOUCAULT, Michel. DELEUZE, Gilles. Theatrum philosophicum, seguido de Repetición y diferencia. Barcelona: Anagrama, 1995.

NIETZSCHE, Friedrich. La genealogía de la moral. Buenos Aires: Alianza, 1998.

WEBER, Max. La ética protestante y el espíritu del capitalismo. Madrid: Istmo, 1998.

Submissão: 25. 05. 2018 / Aceite: 20. 06. 2018.

\footnotetext{
${ }^{5}$ Foucault, Michel, "Theatrum Philosophicum”.
} 